\title{
Study of the interaction of fish myosin with the products of lipid oxidation: The case of aldehydes
}

\author{
Christine Chopin ${ }^{a,{ }^{*}}$, Matenin Kone ${ }^{a}$ and Thierry Serot ${ }^{b}$ \\ a IFREMER, rue de l'île d'Yeu, BP 21105, 44311 Nantes Cedex 3, France \\ ${ }^{\mathrm{b}}$ ENITIAA, rue de la Géraudière, BP 82225, 4432 Nantes Cedex 3, France \\ *: Corresponding author : cchopin@ifremer.fr
}

\begin{abstract}
:
The aim of this study was to assess the modifications of fish myosin induced by interactions with four aldehydes: hexanal, 2-hexenal, 2,4-hexadienal, and 2,6-nonadienal. These compounds are generated during lipid oxidation and are known to have an impact on the functional properties of proteins.

The interactions between protein and aldehydes were highlighted by measuring the content of aldehydes in the gaseous phase by the SPME-GC technique. Results show that the partition of aldehydes between the proteinaceous system and the gas phase decreases with time, except for hexanal. This decrease is proportional to the number of carbons and double bonds.

The reaction between myosin and unsaturated aldehydes induces a decrease in the free sulfhydryl and amino groups of the protein and the formation of dityrosine. The solubility of myosin is significantly affected by the presence of unsaturated aldehydes. All the modifications increase with increasing numbers of carbons and double bonds in the aldehydes.
\end{abstract}

Keywords: Fish myosin; Aldehydes; Interactions; SPME 
Study of the interaction of fish myosin with the products of lipid oxidation: the case of aldehydes

Christine Chopin $^{1 *}$; Matenin Kone ${ }^{1}$; Thierry $\operatorname{Serot}^{2}$

${ }^{1}$ IFREMER, rue de l'île d'Yeu, BP 21105, 44311 Nantes cedex 3

${ }^{2}$ ENITIAA, rue de la Géraudière, BP 82225, 4432 Nantes cedex 3

*Corresponding author: Fax (33)240-374-072; email: cchopin@ifremer.fr

\section{Summary}

The aim of this study was to assess the modifications of fish myosin induced by interactions with four aldehydes: hexanal, 2-hexenal, 2,4-hexadienal, and 2,6nonadienal. These compounds are generated during lipid oxidation and are known to have an impact on the functional properties of proteins.

The interactions between protein and aldehydes were highlighted by measuring the content of aldehydes in the gaseous phase by the SPME-GC technique. Results show that the partition of aldehydes between the proteinaceous system and the gas phase decreases with time, except for hexanal. This decrease is proportional to the number of carbons and double bonds.

The reaction between myosin and unsaturated aldehydes induces a decrease in the free sulfhydryl and amino groups of the protein and the formation of dityrosine. The solubility of myosin is significantly affected by the presence of 
unsaturated aldehydes. All the modifications increase with increasing numbers of carbons and double bonds in the aldehydes.

Keywords: Fish myosin; Aldehydes; Interactions; SPME.

Introduction

Surimi is an intermediate foodstuff, used as a basic ingredient in the manufacture of many similar seafood products. To prepare these products, the surimi must be converted into a gel by the addition of salt followed by heat induced gelation. It is obtained from fish muscle, which is minced, crushed and washed in order to eliminate soluble sarcoplasmic proteins and soluble species like horse mackerel and mackerel (Spencer and Tung, 1994). These fish should not have a particular taste or odor. Surimi is traditionally manufactured from lean fish like blue whiting or Alaska pollock, but the overexploitation of these species led manufacturers to find other sources of supply such as fatty fish species are characterized by a high content of polyunsaturated fatty acids (PUFA) susceptible to oxidative deterioration. The oxidation of PUFA is promoted by the presence of a high level in red muscle. The oxidation of fatty acids leads to the loss of nutritional and organoleptic qualities, as well as textural properties. (Shimizu, Toyohara and Lanier, 1992). 
Primary and secondary lipid oxidation products may react with biological amino constituents such as proteins, peptides, and free amino acids (Pokorny, 1977; Aubourg, Sotelo and Pérez-Martin, 1998). These interactions have an impact on the properties of proteins such as their solubility, state of aggregation, interfacial properties, etc. (Saeed and Howell, 2002).

The aldehydes react with the amino groups of proteins and form Schiff's bases (Carini, Aldini and Facino, 2004). Gardner (1979) showed that the aldehydes increase in the oxidation of lipids (Brunton, Cronin, Monahan and An, 2002). bound preferentially to the thiol groups of the cysteines and the $\varepsilon$-amino groups of lysines. Meynier, Rampon, Dalgalarrondo and Genot (2004) showed that, in the presence of aldehydes (hexenal and hexanal), a rapid and large decrease in the histidyl and lysyl residues of $\beta$ lactoglobulin and of sodium caseinate could be observed. The binding of the amino-acid residues with aldehydes involves a modification of the conformation of the proteins (Meynier, Rampon, Dalgalarrondo and Genot, 2004), which is characterized by a reduction in the fluorescence emitted by the aromatic group of tryptophan. The setting in the presence of myosin and of malonaldehyde (Buttkus, 1967) involves a loss in the free $\mathrm{NH} 2$ groups of the protein, modifying its isoelectric point and thus its solubility. A study on the formation of volatile compounds in the muscle of turkey showed an increase in carbonyl residues in the muscle following an 
It can also be noted that some aldehydes, such as 4-hydroxy-trans-2 nonenal (HNE), are involved in many pathologies like cardiovascular and neurodegenerative diseases, for example Parkinson's disease or arteriosclerosis. Its biological effects are due to its capacity to react with the nucleophilic sites of proteins or peptides. These interactions involve modifications of cellular operation and induction of changes (Carini, Aldini and Facino, 2004).

In most published works, the interaction between volatile compounds and

proteins has been evaluated using headspace GC techniques. Dynamic headspace, involving the trapping of volatiles on polymeric absorbents, and static headspace have been widely used. In recent works, solid-phase microextraction ( SPME) has enabled the measurement of free molecules in the headspace (Fabre, Aubry and Guichard, 2002), of freely dissolved compounds (Vaes, Hamwijk, Ramos, Verhaar and Hemens, 1996), and of oxidized compounds (Kanavouras and Hernadez, 2006; Novak, Bahoo and Miteregger, 2006). However, the use of spectrophotometric techniques allows the mechanism of interactions and the nature of amino-acid groups involved in bonds to be determined (Meynier, Rampon, Dalgalarrondo and Genot, 2004). Interactions between proteins and small ligands, such as volatile compounds induced by lipid oxidation, depend on the nature of the molecules involved (Fabre, Aubry and Guichard, 2002). So, while the interactions between whey proteins and numerous volatile molecules have been widely studied (Gianelli, Flores and Toldra, 2005, Perez, Flores and Toldra, 2006), the bonds between volatile compounds and fish myosin have been rarely investigated. 
The purpose of this study was to investigate the biochemical modifications (quantitative and qualitative aspects) of a target protein, myosin, after reaction with various aldehydes of the alkanal, alkenal, and alkadienal family, secondary products of lipid oxidation.

An assessment of the availability of the aldehydes (liquid-air partition) was carried out by SPME, in order to measure the quantity of these compounds retained by the proteins. The nature of the interactions was tentatively determined by spectrophotometric methods.

\section{Materials and Methods}

\section{Samples}

Fillets from cod, fished in North-east Atlantic area, were purchased from a local fishmonger (Nantes, France). They were preserved in the ice until their use.

\section{Chemicals}

All chemicals were of high purity $(>98 \%)$ and were purchased from Sigma Aldrich, France.

Pure water was obtained from a MilliQ- system (Millipore, France).

Hexanal, (E)-2-hexenal, (E,Z)-2.6-nonadienal (purity >98 \%) and (E,E)-2.4hexadienal (purity $95 \%$ ) were purchased from Sigma Aldrich, France

\section{Myosin isolation}


Myosin was isolated from fresh cod muscle as described by Martone, Busconi, Folco, Trucco and Sanchez (1986), modified by Kristinsson (2001). Electrophoresis was carried out to be ensured of the purity of the myosin.

\section{Electrophoresis analysis}

The purity of the isolated fractions was monitored by sodium dodecyl sulfate polyacrylamide gel electrophoresis (SDS-PAGE), using $4 \%-12 \%$ gels.. Samples $(1 \mathrm{mg} / \mathrm{ml})$, were mixed v/v with SDS reducing buffer, $0.06 \mathrm{M}$ tris- $\mathrm{HCl}$ $\mathrm{pH} 6.8,120 \mathrm{mM}$ DTT, $10 \%$ glycerol and $0.024 \%$ bromophenol blue and deposit in individual wells of vertical gel in mini-protean II electrophoresis unit (Biorad, France). Migration was carried out at $35 \mathrm{~mA}$ constant current for $60 \mathrm{~min}$. The gel was stained with $0.25 \%$ Coomassie blue brilliant R250 in 50\% methanol (v/v) for 5 min and destained in methanol: acetic acid 50\%:10\%. Band identification was done by comparison with molecular weight standards (Full range rainbow, Amersham Life Science.)

Myosin was solubilized in a $50 \mathrm{mM}$ phosphate buffer, $\mathrm{pH} 7.0,0.6 \mathrm{M} \mathrm{NaCl}$. Measurement of protein concentration was carried out by the Lowry method (1951).

Aldehydes were solubilized in ethanol/water (30:70) and mixed with protein to 
flasks, hermetically closed using a screwed cap with PTFE liner. The flasks were completely filled to avoid partition between the liquid and the gaseous phase. The solutions were stirred close to $800 \mathrm{rpm}$ for different times between 0 and 72 hours. All the experiments were performed at $25{ }^{\circ} \mathrm{C}$. Blanks were prepared with myosin solution without aldehydes and with aldehyde solution without myosin.

Determination of free aldehyde concentration by Solid Phase Micro Extraction: SPME

The conditions of extraction were optimized during previous experiments.

Samples $(4 \mathrm{ml})$ were placed in specific $15 \mathrm{ml}$ SPME vials and allowed to reach (Supelco) was exposed to the gaseous phase for $30 \mathrm{~min}$. The aldehydes were desorbed after insertion of the fiber into the $\mathrm{GC}$ injector set at $260{ }^{\circ} \mathrm{C}$. Desorption of the compounds was performed for 3 min (injector in splitless mode)

Aldehyde concentration was obtained by calculation from calibration curves established for the four aldehydes studied.

\section{GC-FID analysis}

A Varian star 3900 equipped with a split-splitless injector and a Flame Ionization Detector was used. A fused-silica capillary column DB wax: (J \& W Scientific) $30 \mathrm{~m}$ length, $0.32 \mathrm{~mm}$ i.d. and $1 \mu \mathrm{m}$ film thickness was used. The 
injector was kept at $260{ }^{\circ} \mathrm{C}$ and the detector was maintained at $250{ }^{\circ} \mathrm{C}$. The carrier gas was helium $(1.0 \mathrm{ml} / \mathrm{min})$. The temperature of the $\mathrm{GC}$ oven was started at $50{ }^{\circ} \mathrm{C}$ and increased to $240{ }^{\circ} \mathrm{C}$ at a rate of $6{ }^{\circ} \mathrm{C} / \mathrm{min}$.

Myosin solubility

Solution of myosin $(1 \mathrm{mg} / \mathrm{ml})$, was centrifugated at $10.000 \mathrm{~g}, 10 \mathrm{~min}$ at $4^{\circ} \mathrm{C}$ and protein content of supernatant was determined with Bradford's method (Bradford, 1976) the results were expressed as the ratio of the protein content in the supernatant over the initial protein content.

169

\section{Determination of total sulfhydryl content}

Total sulfhydryl content was determined using 5-5'-dithio-bis (2-nitrobenzoic acid) (DTNB) according to the method of Ellman (1959) as modified by Benjakul and al. (1997). To $1 \mathrm{ml}$ of protein solution $(1 \mathrm{mg} / \mathrm{ml})$ was added $9 \mathrm{ml}$ of 0.2 M Tris-HCL buffer, $\mathrm{pH} 6.8$, containing urea (8 M), SDS (2\%), and EDTA $(10 \mathrm{mM})$. The mixture was homogenized and $4 \mathrm{ml}$ was taken. $0.4 \mathrm{ml}$ of DTNB $(0.1 \%$ in Tris-HCl buffer, $\mathrm{pH} 8.0)$ was added. The mixture was shaken and incubated at $40{ }^{\circ} \mathrm{C}$ for 25 minutes. The control was carried out by replacing the sample with a $0.6 \mathrm{M}$ solution of $\mathrm{KCl}$. The O.D. was read at $412 \mathrm{~nm}$. The extinction coefficient of the reagent is $13600 \mathrm{M} . \mathrm{cm}^{-1}$.

\section{Determination of carbonyl content}


Protein carbonyl content in myosin was determined according to the method of Oliver, Ahn, Moerman, Golstein and Stadtman with slight modifications. 500 $\mu 1$ of $10 \mathrm{mM}$ DNPH solution (in $2 \mathrm{M} \mathrm{HCl}$ ) was added to $500 \mu \mathrm{l}$ of protein solution ( $1 \mathrm{mg} / \mathrm{ml}$ ), $500 \mu \mathrm{l}$ of $2 \mathrm{M} \mathrm{HCl}$ was added for the control. The tubes were left 15 minutes at room temperature and homogenized every 5 minutes. Then, $500 \mu 1$ of TCA $(30 \%)$ was added. After shaking, the tubes were placed in ice for $10 \mathrm{~min}$. In order to eliminated the excess DNPH the incubated samples were coefficient used was 22000/M.cm.

\section{Determination of amino groups content} Amino groups content was determined according to the modified method of Bhaskar et al (2002) To $1 \mathrm{ml}$ of protein solution, $1 \mathrm{ml}$ of sodium tetraborate, 2 $\%$ in solution, was added to facilitate the access to free $\mathrm{NH}_{2}$ groups, $0.25 \mathrm{ml}$ of a $13 \%$ solution of dinitrofluorobenzene (DNFB) in ethanol was added and after homogenization the mixture was incubated at $60{ }^{\circ} \mathrm{C}$ for 10 minutes. The with $10 \mathrm{M} \mathrm{HCl}$. Absorbance was read at $410 \mathrm{~nm}$ using a Unicam UV2 
spectrometer. The content of free $\mathrm{NH}_{2}$ (mmole) was obtained by comparison with a calibration curve carried out with solutions of glycine ranging between 0 and $6.10^{-4} \mathrm{mM}$.

\section{Statistical treatment}

All experiments were performed in triplicate

Data acquisition and statistical treatment were performed with Statgraph 5.0 software (Manugistics, Rockville, MD). Protein solubility, gas-liquid phase partition coefficient, estimated concentrations of amino, sulphydryl and carbonyl groups were averaged for each experiment. One way analyses of variance were performed on these average values with a confidence level of 95\% and they were then compared by least significance difference tests. For each table or figure, data are presented with standard error.

\section{Results and discussion}

\section{Characterization of binding between aldehydes and myosin by SPME}

On the basis of SPME determination, no significant variation in the content was observed in the gaseous phase after 72 hours of contact between hexanal and myosin. This result shows that there is probably no interaction between hexanal and fish myosin. Therefore, the partition coefficient of this aldehyde was not modified in the presence of myosin. Thereafter, hexanal was not used for the biochemical analysis. 
On the other hand, significant modifications of the concentrations of 2-hexenal, 2,6-nonadienal and 2,4-hexadienal in the gaseous phase were observed according to the time when these compounds were placed in the myosin solution. An almost linear slow decrease in 2-hexenal was observed between 0 and 72 hours (Figure 1). For 2,4-hexadienal, the decrease was more rapid between 0 and 48 hours and, after this time, the change in the concentration was slow reaching $0.22 \mu \mathrm{g} / \mathrm{ml}$ at $72 \mathrm{~h}$ (Figure 2). 2,6-nonadienal was not detected in the gaseous phase after 48 hours of contact with fish myosin solution (Figure 3).

The interaction between 2.6-nonadienal and fish myosin is very significant. After 24 hours, $75 \%$ of the initial aldehyde was bound with myosin while only $40 \%$ of 2 - hexadienal and $20 \%$ of 2-hexenal was retained by fish myosin.

These results could show that the interaction between protein and aldehydes greatly depends on the structure of the aldehyde. It seems that the number of double bonds is important because hexanal did not react with myosin while the speed of the reaction with 2,4-hexadienal was double that of 2-hexenal. According to Meynier, Rampon, Dalgalarrondo and Genot (2004), covalent binding between aldehydes and whey proteins is the consequence of the addition of double bonds to the imidazole ring of histidyl residues.

The reactivity also seems to increase with the length of the carbon chain because the speed of the reaction with 2,6-nonadienal is almost twice that with 2,4 hexadienal. Reiners, Nicklaus and Guichard (2000) have shown that, in the case of $\beta$ lactoglobulin, the increase in the hydrophobic chain length of volatile compounds increases the affinity for the protein. 
Furthermore, 2,6-nonadienal presents a conformation of the cis type compared to 2,4-hexadienal, which could partly explain its greater reactivity with myosin, considering these two aldehydes have the same number of double bonds.

\section{Effect of aldehydes on myosin solubility}

The solubility of myosin decreases in the presence of the studied aldehydes (Figure 4) but the results did not show a significant difference for 2-hexenal and 2,4-hexadienal, even after $48 \mathrm{~h}$.. After $24 \mathrm{~h}$, the solubility of myosin in the presence of 2,6-nonadiénal was close to 0. 2,6-nonadienal might induce the polymerization of proteins effectively (Figure 4). No change of the solubility of myosin was monitored in the control without aldehydes during this period.

The decrease in solubility is due to the formation of aggregates between the different chains of myosin (Tironi et al, 2004). 2,6-nonadienal could create more change in the conformation of myosin, which would result in a greater accessibility of the aldehyde and a possible reactivity with the amino acid side chains acting as nucleophiles. The type of protein modification can lead to changes in the isoelectric point and consequently to changes in its solubility properties. 
Figure 5 illustrates the variation in the free amino groups of myosin, according to time. In the presence of aldehydes, a significant reduction in the free amino groups during 48 hours compared to the control is expected. No difference was observed between 2-hexenal and 2,4-hexadienal. Thus, the number of double bonds had no influence on the reaction and on the content of the free amino 
The results of the study concerning the evolution according to time of the sulfhydryl groups of myosin (Figure 6) show a slight decrease of these groups even in the absence of the aldehydes. This decrease could be due to a spontaneous oxidation of these groups. However in the presence of the three aldehydes a significantly stronger reduction in these groups could be observed after 24 hours Moreover, the results showed that 2,4-hexadienal and 2-hexenal had an equivalent reactivity after 6 hours. Ichihashi, Osawa, Toyokuno and Ushida (2001) affirmed that the 2-alkenals represent a category of aldehydes having a strong reactivity with the sulfhydryl groups of cysteine because of the possibility of interaction between the protein and two centers of reaction on the

aldehydes (carbons 1 and 3). This observation could explain the equivalent reactivity of 2-hexenal compared to 2,4-hexadienal with the $\mathrm{SH}$ groups of myosin, in spite of the difference of a double bond between the two aldehydes. The presence of 2,6 nonadienal also involved a decrease in the SH groups of myosin (Figure 6). At 24 hours, the quantity of free groups remaining in myosin in contact with 2,6-nonadienal was greater than with 2,4-hexadienal and 2hexenal. Usually, cysteine is the amino acid most involved in the interactions between proteins and compounds produced by lipid oxidation (Liu and Xiong, 2000). According to this author, the myosin has 42 sulphydryl groups and the majority are accessible to the chemical reagents used. 
Carbonyl groups can appear on proteins following various reactions (Liu and Xiong, 2000) by direct oxidation of amino acids, like lysine, proline, arginine, etc. or during reaction with aldehydes.

An increase in the content of carbonyl groups in myosin was observed in presence of aldehydes (Figure 7). This modification was significantly greater in the samples containing 2,6- nonadienal and 2-hexenal than in those containing 2,4-hexadienal (Figure 7). The increase of carbonyl is probably due to the reaction of aldehydes with free amino groups as mentioned previously. Furthermore, the interaction of aldehydes with myosin could involve an opening of the chains of myosin making it possible to uncover new reactive sites. Partitioning also takes into account the carbonyl groups of aldehydes, but their weak concentration does not explain the difference with the control. After 48 hours, a reduction in this level was observed. This result has already been found by Liu and Xiong (2000) and could be explained by a mechanism of formation of bridges between free carbonyls and $\mathrm{NH}_{2}$ groups.

The decrease of the partition between the liquid and the gaseous gas of 2,6nonadienal, 2-hexenal and 2,4-hexadienal observed thanks to SPME, allowed to highlight the occurrence of interactions between fish myosin and products of lipid oxidation like aldehydes. 
It was shown that these interactions lead to a decrease of protein solubility, probably due to aggregations. It appears clearly that amino and sulphydryl groups were involved in these interactions. It can be noted in particular the reaction of aldehydes with the free lysyl residues according to the Michael addition pathway.

The results of this study show also that the presence of double bond in the aldehyde chain is necessary so that a reaction takes place and, moreover, that the binding occurs more quickly with aldehydes having a long chain, presenting a double bond, cis conformation.

The loss of solubility and the blocking of the amino and sulfhydryl groups of myosin act on its functional properties by preventing, in particular, the formation of a protein network, essential for the manufacture of processed foods containing surimi. It is thus essential to avoid, either by refrigeration or by the addition of antioxidant, the formation of lipid oxidation products during the 356 production and conservation of surimi. 
References

Aubourg, S.P., Sotelo, C.G. and Pérez-Martin, R. (1998). Assessment of quality

changes in frozen sardine (Sardina pilchardus) by fluorescence detection.

Journal of the American Oil Chemists' Society, 75, 578-580.

Bhaskar K.,. Pavankumar Shetty A, Shareef M. M., Ramamohan Y. and.

Taranath Shetty K. (2002). Dinitrophenol derivatization of proteolytic products

and its application in the assay of protease(s) activity. Journal of Neuroscience

Methods, 120, 2, 155-161

Benjakul, S., Seymour, T.A. and Morrissey, M.T. (1997). Physicochemical

Science, 62(4), 729-733.

Bradford, M.M. (1976). A rapid and sensitive method for the quantitation of Analytical chemistry, 72, 248-254.

Brunton, N.P., Cronin, D.A., Monahan, F.J. and An, H.J. (2002). Volatile components associated with freshly cooked and oxidized off-flavours in turkey breast meat. Flavour and Fragrance Journal, 17(5), 327-334.

Buttkus, H. (1967). The reaction of myosin with malonaldehyde. Journal of Food Science, 32, 432-434.

Carini, M., Aldini, G. and Facino, R.M. (2004). Mass spectrometry for detection of 4-hydroxy-trans-2-nonenal (HNE) adducts with peptides and proteins. Mass Spectrometry Review, 23(4), 281-305. 
Ellman, G.L. (1959). Tissue sulphydryl groups. Archives Biochemistry Biophysics, 82, 70-77.

Esterbauer, H., Schaur, R.J. and Zollner, H. (1991) Chemistry and biochemistry of 4-hydroxynonenal, malonaldehyde and related aldehydes. Free Radical Biology and Medicine, 11(1), 81-128.

Fabre, M., Aubry, V. and Guichard, E. (2002). Comparison of different methods: Static and dynamic headspace and solid-phase microextraction for the measurement of interactions between milk proteins and flavour compounds with an application to emulsions. Journal of Agriculture and Food Chemistry, 50(6), $1497-1501$.

Gardner, H.W. (1979). Lipid hydroperoxide reactivity with proteins and amino acids: A review. Journal of Agriculture and Food Chemistry, 27, 220-229.

Gianelli, M.P., Flores. M. and Toldra, F. (2005). Interaction of soluble peptides and proteins from skeletal muscle with volatile compounds in model systems as affected by curing agents. Journal of Agricultural and Food Chemistry, 53(5), $1670-1677$.

Ichihashi, K., Osawa, S., Toyokuno, S. and Ushida, K. (2001). Endogenous formation of protein adducts with carcinogenic aldehydes - Implications for oxidative stress. Journal of Biological Chemistry, 276(26), 23903-23913.

Lowry, O. H., Rosebrough N. J, Farr A.L. and Randall R. J. (1951). Protein measurement with the Folin-Phenol reagents. Journal of Biological Chemistry. $193,265-275$. 
Kanavouras, A. and Hernadez, R.J. (2006). The analysis of volatiles from thermally oxidized virgin oil using dynamic sorption-thermal desorption and solid phase microextraction techniques. International Journal of Food Science and Technology, 41(7), 743-750.

Kristinsson H.G. (2001). Evaluation of different methods to isolate cod (Gadus morhua) muscle myosin. Journal of Food Biochemistry, 25, 249-256.

Liu, G. and Xiong, Y.L. (2000). Oxidatively induced chemical changes and interactions of mixed myosin, beta-lactoglobulin and soy $7 \mathrm{~S}$ globulin. Journal of the Science of Food and Agriculture, 80(11), 1601-1607.

Martone, C.B., Busconi L., Folco, E.J., Trucco, R.E. and Sanchez J.J. (1986). A simplified myosin preparation from marine fish species. Journal of Food Science, $51, \mathrm{n}^{\circ} 6,1554-1555$.

Meynier, A., Rampon, V., Dalgalarrondo, M. and Genot, C. (2004). Hexanal and $\mathrm{t}-2$ hexenal form covalent bonds with whey proteins and sodium caseinate in aqueous solution. International Dairy Journal, 14(8), 681-690.

Novak, J., Bahoo, L. and Miteregger, U. (2006). Composition of individual essential oil glands of savory (Salureja hortensis L. Lamiaceae) from Syria. Flavour and Fragrance Journal, 21(4), 731-734.

Oliver, C.N.; Ahn, B.W.; Muerman, E.J.; Golstein, S. and Stadtman, E.R. (1987). Aged-related changes in oxidized proteins. Journal of Biological Chemistry,.262, 5488-5491.

Perez, J.M., Flores, M. and Toldra, F. (2006). Model study on the efficacy of protein homogenates from raw pork muscle and dry-cured ham in binding 
selected flavour compounds. Journal of Agricultural and Food Chemistry, 54(13), 4802-4806.

Pokorny, J. (1977). Interactions of oxidized lipids with protein. La Rivista Italiano Delle Sostanze Grasse, IV, 389-393.

Reiners, J., Nicklaus, S. and Guichard, E. (2000). Interactions between betalactoglobulin and flavour compounds of different chemical classes. Impact of the protein on the odour perception of vanillin and eugenol. Lait, 80(3), 347360.

Saeed, S. and Howell, N.K. (2002). 1.2 lipoxygenase activity in the muscle tissue of Atlantic mackerel (Scomber scombrus) and its prevention by antioxidants. Journal of the Science of Food and Agriculture, 81, 745-750. Sharp, A. and Offer G. (1992). The mechanism of formation of gels from myosin molecules. Journal of Science of Food and Agriculture, 58, 63-73. Shimizu, Y., Toyohara, H. and Lanier, T.C. (1992). Surimi production from fatty and dark-fleshed fish species. In Surimi Technology (pp 181-207). Marcel Dekker Inc, New-York. Spencer, K.E. and Tung, M.A. (1994). Surimi processing from fatty fish. In Seafoods: Chemistry, Processing Technology and Quality (pp 288-319). Shahidi, F. \& Botta, J.R. (Eds), London, Blackie Academic \& Professional, Tironi, V.A., Lopez, L.B., Pellegrino, N., Anon, M.C. and Tomas, M.C. (2004). Malonaldehyde-induced microstructural modifications in myofibrillar proteins of sea salmon (Pseudopercis semifasciata). Journal of Food Science, 69(7), C519-C523. 
Vaes, W.H.J., Hamwijk, C., Ramos, E.U., Verhaar, H.J.M. and Hermens, J.L.M. (1996). Partitioning of organic chemicals to polyacrylate coated solid phase microextraction fibers. Kinetic behaviour and quantitative structure property relationship. Analytical Chemistry, 68(24), 4456-4462. 


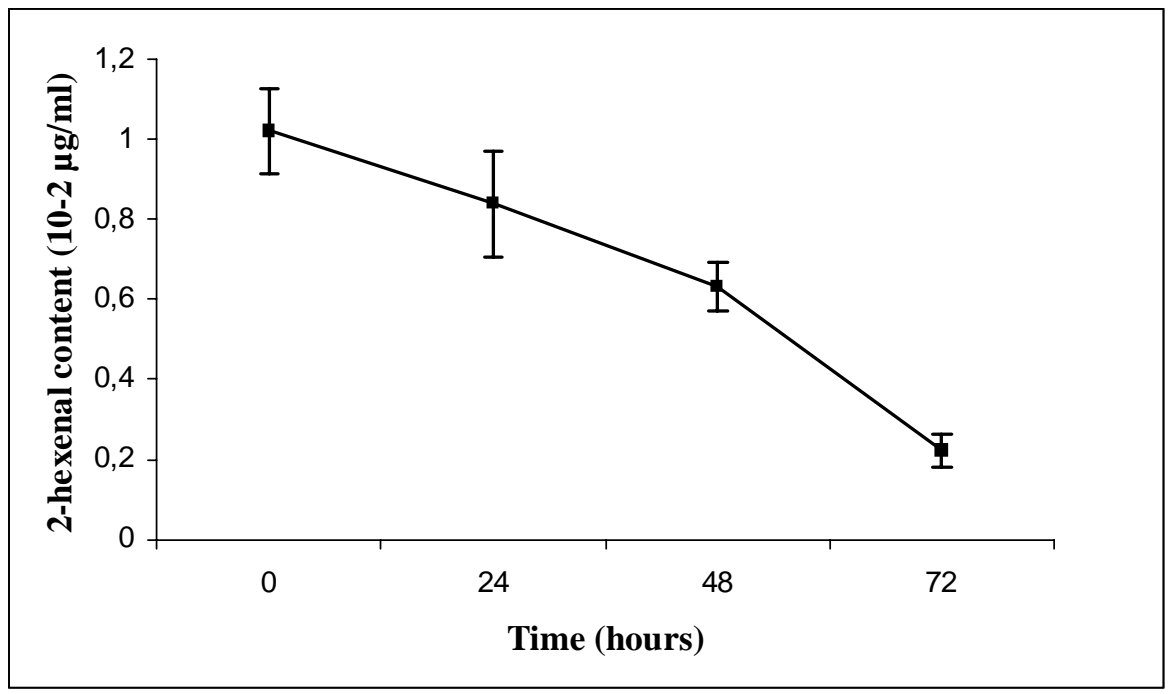

Figure 1: Headspace concentration of 2-hexenal $\left(10^{-2} \mu \mathrm{g} / \mathrm{ml}\right)$ in the presence of myosin solution $(1 \mathrm{mg} / \mathrm{ml})$ as a function of time. (Bars represent the standard deviation from 3 determinations) 




Figure 2: Headspace concentration of 2,4-hexadienal $\left(10^{-2} \mu \mathrm{g} / \mathrm{ml}\right)$ in the presence of myosin solution $(1 \mathrm{mg} / \mathrm{ml})$ as a function of time. (Bars represent the standard deviation from 3 determinations) 


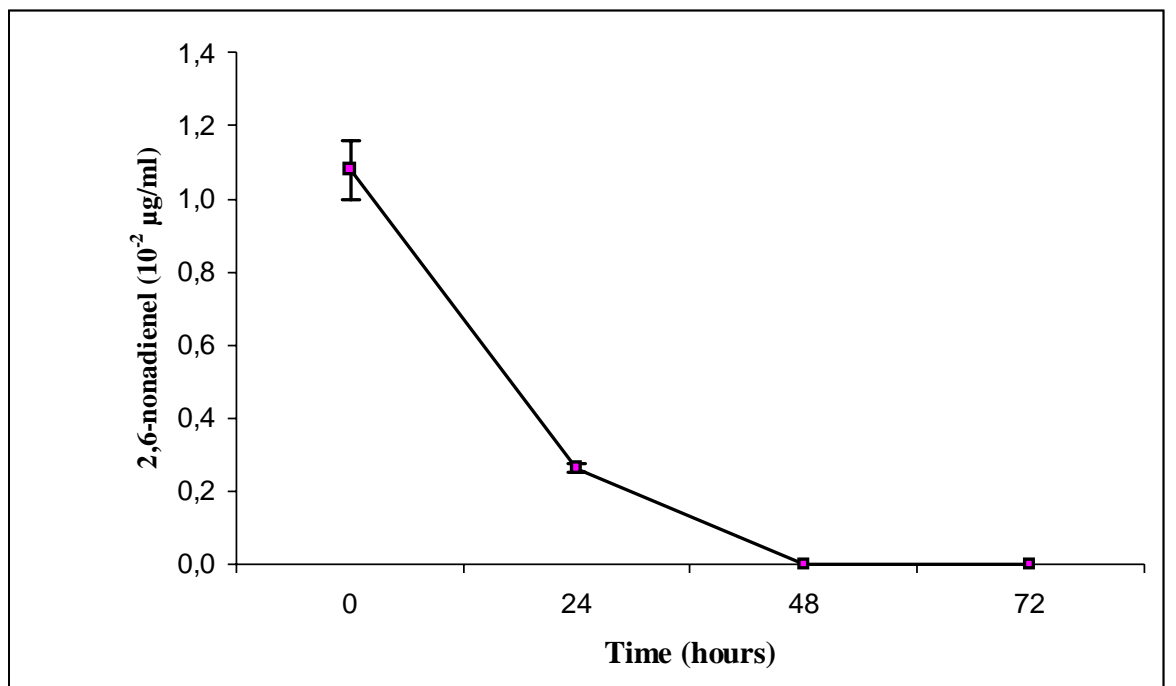

Figure 3: Headspace concentration of 2,6-nonadienal $\left(10^{-2} \mu \mathrm{g} / \mathrm{ml}\right)$ in the presence of myosin solution $(1 \mathrm{mg} / \mathrm{ml})$ as a function of time. (Bars represent the standard deviation from 3 determinations) 


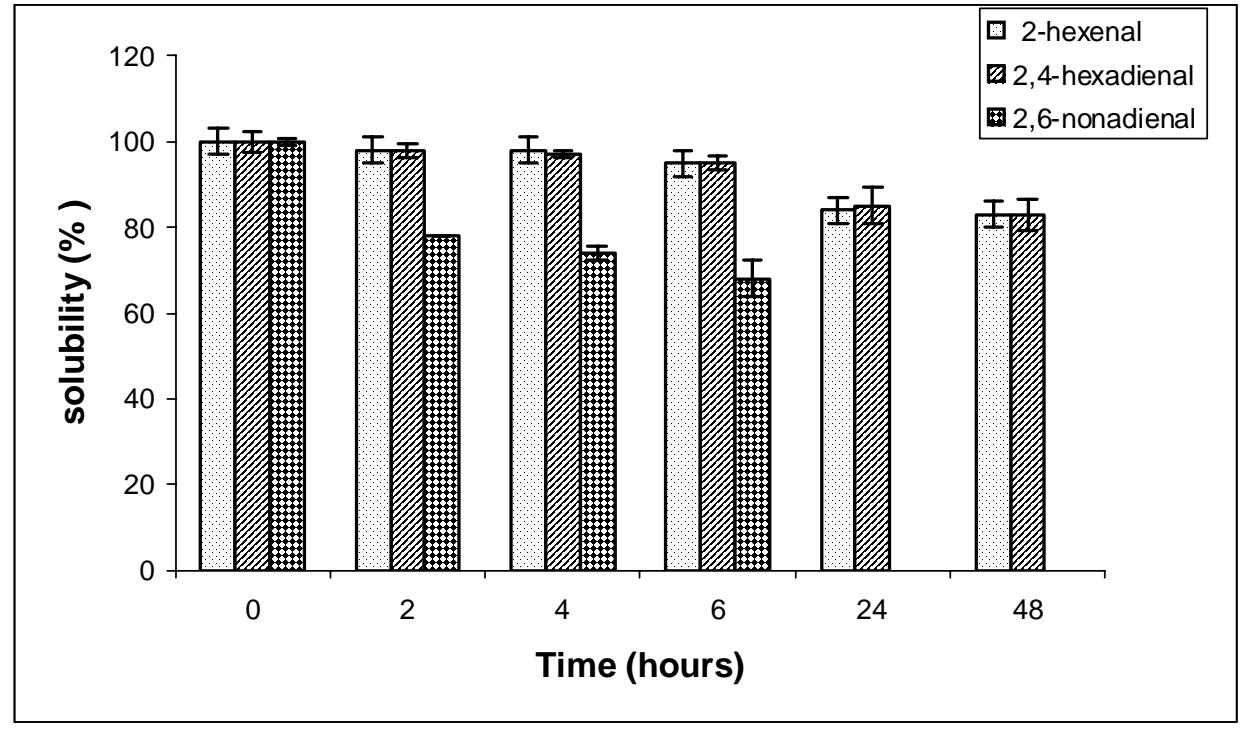

Figure 4: Change in the solubility of myosin over time in the presence of 2-hexenal, 2,4-hexadienal and 2,6-nonadienal (expressed as a percentage of the control) (Bars represent the standard deviation from 3 determinations) 


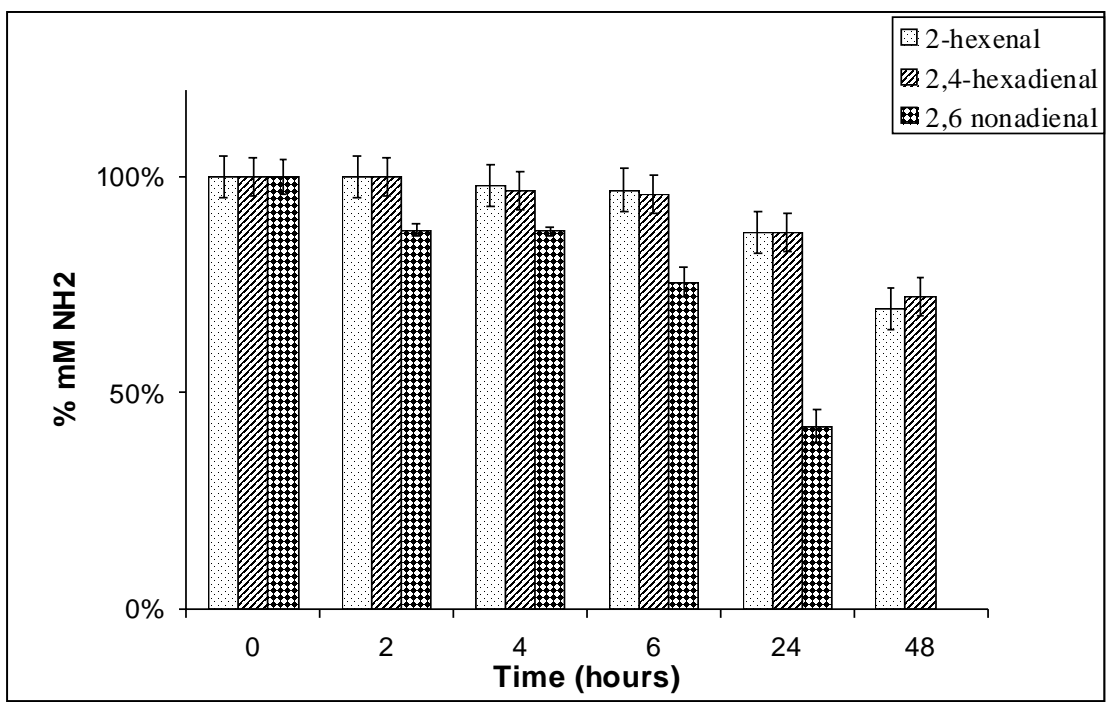

Figure 5: Change in the free $\mathrm{NH}_{2}$ groups of myosin over time in the presence of 2hexenal, 2,4-hexadienal and 2,6-nonadienal (expressed as a percentage of $\mathrm{NH}_{2}$ groups in the control) (Bars represent the standard deviation from 3 determinations). 


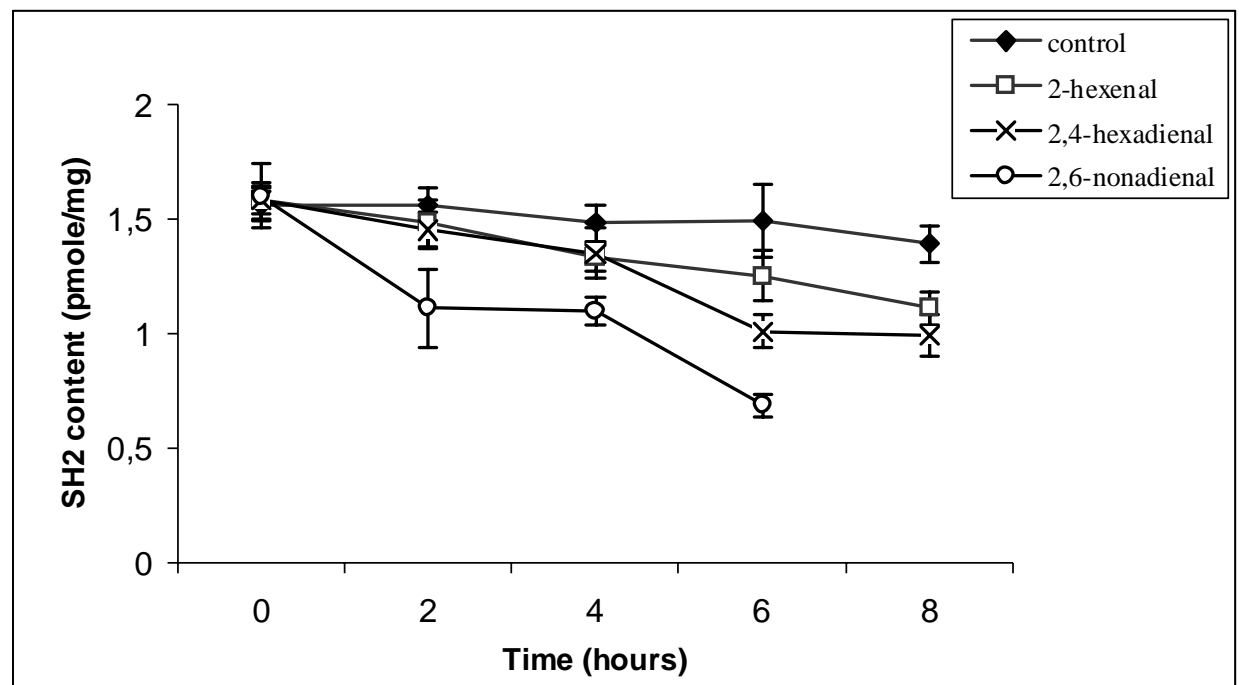

Figure 6: Change in the free sulfhydryl groups of myosin over time in the presence of 2-hexenal, 2,4-hexadienal and 2,6-nonadienal. (Bars represent the standard deviation from 3 determinations) 


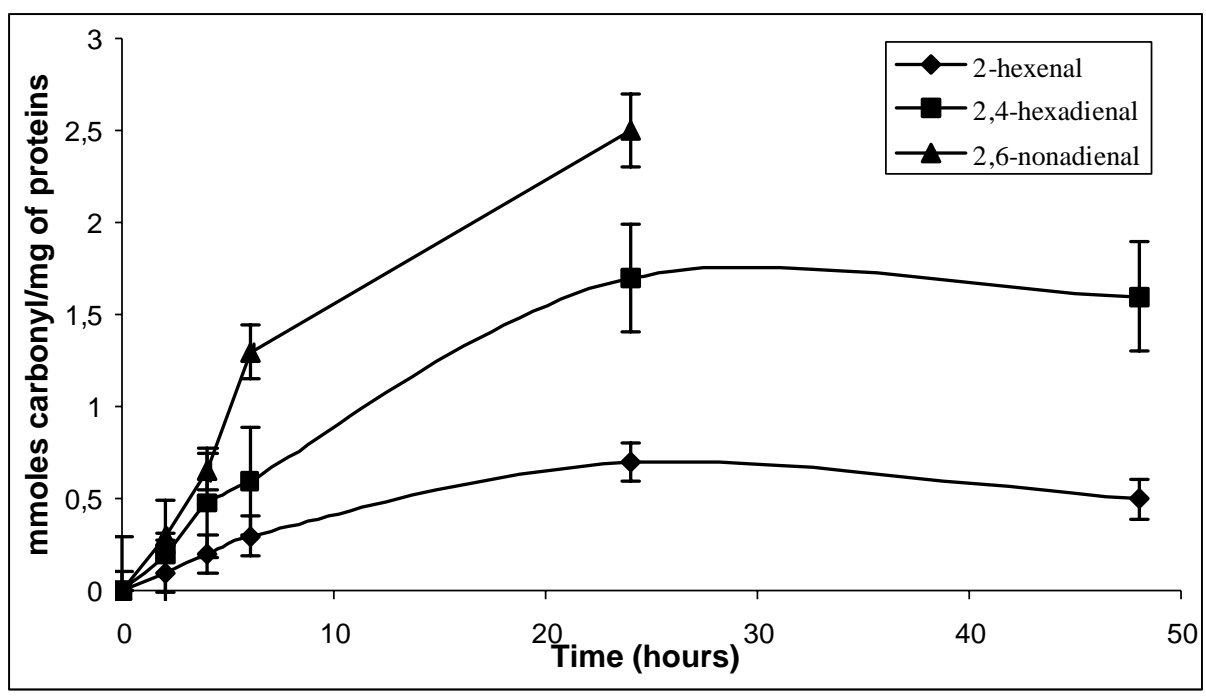

Figure 7: Change in the free carbonyl groups of myosin over time in the presence of the aldehydes expressed as the difference between the levels in the samples and the level in the control. (Bars represent the standard deviation from 3 determinations) 